\title{
COGNITIVE MAPS: WHAT ARE THEY AND WHY STUDY THEM?
}

\author{
ROBERT M. KITCHIN \\ Department of Geography, University College of Swansea, Wales SA2 8PP, U.K.
}

\begin{abstract}
It is often implicitly assumed by researchers that their readers understand what cognitive map and cognitive mapping are, and their justification for study. This paper differs in this respect by explaining explicitly the 'what' and 'why' questions often asked, demonstrating cognitive mapping's multidisciplinary research worth. First, it examines questions concerning what cognitive maps are, the confusion inherent from the use of the term 'map', and the usage and reasons for alternative expressions. Second, it examines the theoretical applications or conceptual research, concerning cognitive maps role in the influencing and explaining spatial behaviour; spatial choice and decision making; wayfinding and orientation; and the cognitive maps utility and role as a mnemonic and metaphorical devise; a shaper of world and local attitudes and perspectives; and for creating and coping with imaginary worlds. Third, it discusses cognitive mapping's practical and applied worth, concerning the planning of suitable living environments; advertising; crime solving; search and rescue, geographical educational issues, cartography and remote sensing; and in the designing and understanding computer interfaces and databases, especially Geographical Information Systems (GISs).
\end{abstract}

\section{Introduction}

This paper aims to discuss explicitly what cognitive maps are and their justificalion for study. It is intended as a broad overview of the subjects multidisciplinary nature and its current and potential applications, and to highlight the inherent definitional problems associated with such a wide range of users. Such a review is necessary to stimulate and encourage more collaboration between researchers from different backgrounds, reveal applications that individually we may have not been aware of, and to try and strengthen definitional problems, hopefully introducing an element of conformity in term use, so far lacking because of a multidisciplinary research background. It is not intended as an in-depth review of specific applications, nor as a platform to discuss, critique or explain the many other issues, such as the many theories concerning learning, development, content, form, structure, thought, brain location and measurement of cognitive map knowledge. It deliberately contains many references to allow and promote crossdisciplinary reading.

\section{What are Cognitive Maps and Cognitive Mapping?}

The traditional definition used and accepted by many researchers states that:

cognitive mapping is a process composed of a series of psychological transformations by which an individual acquires, stores, recalls, and decodes information about the relative locations and attributes of the phenomena in his everyday spatial environment (Downs \& Stea, 1973a, p. 7)

Cognitive mapping can thus be thought of as a marriage between spatial and environmental cognition, where spatial cognition is defined as:

...the knowledge and internal or cognitive representation of the structure, entities, and relations of space; in other words, the internalized reflection and reconstruction of space in thought (Hart \& Moore, 1973, p. 248)

and environmental cognition refers to:

the awareness, impressions, information, images, and beliefs that people have about environments...it implies not only that individuals and groups have information and images about the existence of these environments and of their constituent elements, but 
also that they have impressions about their character, function, dynamics, and structural interrelatedness, and that they imbue them with meaning, significance, and mythical-symbolic properties (Moore \& Golledge, 1976, p. xii).

In this way cognitive mapping refers to a 'place cognition' as described by Hart and Conn (1991), so that rather than dealing exclusively with either the spatial aspect or the environmental aspect of how we think about everyday environmental and geographical data, it combines the relevant sections of the two so that:

...one is brought closer to meaning and action, for "place" is the focus of human intentions. Consequently, the study of place leads us to the simultaneous investigation of thinking, feeling, and acting in the environment (italics added) (Hart \& Conn, 1991, p. 278)

Cohen (1985, p. 9) sums such a 'place cognition' as:

A union of spatial knowledge, social knowledge, and an understanding of the physical and social nature of environments-all in relation to...cognitive func tioning.

Tolman (1948) first used the term 'cognitive map', to describe how rats, and by analogy, humans behaved in the environment. He hypothesized that we construct a map-like representation within the 'black box' of the nervous system which is used to guide our everyday movements. This representation is actually structured in the same way as a cartographic map, gaining euclidean properties with repeated experience. The term gained little recognition until it was resurrected by experimental and development psychologists in the early 1970s, and although used with extreme caution for a time owing to behaviourist connotations (Allen 1985), the phrase eventually took hold, especially among geographers to whom the term had appeal (Downs \& Stea, 1973a, Boyle \& Robinson, 1978).

At its most general, a cognitive map is a mental construct which we use to understand and know the environment (Kaplan, 1973a). The term assumes that people store information about their environment which they then use to make spatial decisions. Tversky (1992, p. 134) suggests that at its broadest definition a cognitive map is the:

cognitive apparatus that underlies...behaviour.

while Stea and Blaut (1973, p. 227) describe it as a construct which enables a person:

to predict the environment which is too large to be perceived at once, and to establish a matrix of environmental experience into which a new experience can be integrated.
In effect, a cognitive map is a mental devise and store which helps to simplify, code and order the endlessly complex world of human interaction with the environment (Walmsley, et al., 1990). Downs and Stea (1973a) refer to them as "convenient shorthand symbols that we all subscribe to, recognise and employ'. This subscription does not have to be performed consciously, but can be if necessary. It is in effect a mental representation of spatial/environmental knowledge (N.B. the term representation is not meant to imply image).

This construct is thought to exist because it is assumed that people store information about their environment which they then use to make spatial decisions which guide behaviour, and is, in effect responsible for geographical 'survival' knowledge. (Stea 1969; Kaplan 1973b). Kaplan (1973b) similarly hypothesizes that cognitive maps develop as a means of quick and efficient mechanism for handling information thus giving man a selective advantage in a difficult and dangerous world. They -re in effect 'evolutionary adaptive' giving man a sense of place' necessary for survival (Stea, 1976). Downing (1992, p. 442) in a discussion of images wrote a passage which neatly describes cognitive maps. Cognitive maps:

suspend impressions, thoughts, feelings and ideas until, for some reason, consciously or unconsciously, the mind solicits, changes, and often distorts or manipulates its contents for some immediate purpose. In this way cognitive maps (images) allow us to bridge time, by using past experiences to understand present and future situations.

Cognitive maps, though, are not just a set of spatial mental structures denoting relative position, they contain attributive values and meanings. As Wood and Beck (1989) explain, the cognitive map is not independent of meaning, of role, of function, of need, of end, and of purpose. This distinction leads to the conclusion that a cognitive map includes knowledge about places as well as knowledge consisting of spatial relationships (Kaplan, 1976) and that cognitive maps involve the integration of images, information and attitudes about an environment' (Spencer \& Blades, 1986 p. 240). They are in effect 'representations of objects and their associations' involving generic and motivational information (Kaplan, 1973b). As Spencer et al. (1989, p.108) state:

... cognitive maps are not isolated and contextless entities: they are formed during purposive activity in the everyday world of the child, and, in as much as they encode the resources, valued friends, memories, and aspirations as well as factual information about 
geographical layout and routes, they should perhaps better be described as cognitive/affective maps.

Golledge and Timmermans (1990) have reported that cognitive maps are in effect a series of knowledge structures which consist of different levels of detail and integration. These knowledge structures develop with age and education, thus increasing the information held. By combining different knowledge structures and information using cognitive processes relating to perception, storage, retrieval and reorganization that interact with memory structures a cognitive map is formed for specific tasks (Golledge $e t$ al., 1985). This, if interpreted literally means there is no one cognitive map in memory but rather we construct them for specific events (Siegel $\&$ Cousins, 1985). In this respect cognitive maps are dynamic.

It must also be recognized that cognitive maps are not independent of time and space and that 'since each environment exists in a time-space context, so too will cognitions of those environments' (Moore \& Golledge, 1976 p. 11). In summary then, and for the purpose of this paper, cognitive maps constructed from the knowledge store contain information concerning, spatial relations and environmental attributive data which reside within a space-time context allowing the possessor to operate within an environment and to process environmental and geographical data. They are 'complex, highly selective, abstract and generalised' structures which are incomplete, distorted, schematised, and augmented' (Downs \& Stea, 1973c, p.18)

\section{Problematic definitions and the confusion created using the term 'map'}

Buttenfield (1986, p. 238) has reported that the cognitive map is not in fact the internal representation of the environment but rather the external product of measurement.

Because it reflects an internal, spatial memory, the external reported information reflects a cognitive process, and so is called a cognitive map.

Gatrell (1983) has noted this confusion as to whether a cognitive map is an inferred internal representation or an elicited external representation. Buttenfield's position is not advocated here: a cognitive map refers to the internal thinking of the everyday spatial environment. The external form of this thought, elicited through an appropriate methodology, is called a spatial product, a term initially used by Liben (1981) which has gained some standard recognition.
Kuipers (1978) has called 'common-sense knowledge' a cognitive map and again this is not strictly true. Kuipers (1978, p. 129) defines common-sense knowledge as:

knowledge about the physical environment that is acquired or used, generally without concentrated effort, to find and follow routes from one place to another, and to store and use the relative positions of places.

This implies the ability to make inferences and propositions, both of which are not necessarily needed to be able to complete a cognitive mapping exercise, but rather exercises needing the use of configurational knowledge (knowledge of the associations between, and relative locations of places).

Although there is a general acceptance as to what cognitive mapping refers to, there still remains much misunderstanding in the use of the word 'map' in the term 'cognitive map', and thus the form of cognitive maps. The form of cognitive maps (images, conceptual-propositional, dual coding, holograms, genetic coding) are not investigated within this paper, but there are four main viewpoints that can be adopted in explaining the use of the term 'map' which has caused confusion and misuse in the past (see the debate between Graham 1976, 1981 and Downs 1981):

(1) Is it the case that the cognitive map is a cartographic map (Explicit statement)?

(2) Is it the case that the cognitive map is like a cartographic map? (Analogy)

(3) Is it the case that a cognitive map is used as if it were a cartographic map (Metaphor)?

(4) Is it the case that the cognitive map has no real connections with what we understand to be a map, i.e. a cartographic map, and is neither an explicit statement, analogy or a metaphor but rather an unfortunate choice of phrase: 'a convenient fiction?' (Siegel, 1981). In effect just a hypothetical construct.

Explicit Statement: A cognitive Map is a map. O' Keefe and Nadel (1978) have hypothesized that the hippocampus, a part of the brain associated with long-term memory, is a cognitive map, and that this map is a three-dimensional, euclidean model of the world, with rigid geometrical properties. This belief is based on findings of several experiments which found the activity of the rats hippocampal neurons correlated with the rats location in the maze. Other neuroscientists such as Lieblich and Arbib (1982) have agreed that the hippocampus does play a role in wayfinding but are not so sure of its role as a store of the whole 'world graph' 
(cognitive map), but rather argue that it holds a 'chart of the local neighbourhood that must be presumably read from a whole atlas stored in longterm memory' and is effectively a situation recogniser' (Lieblich \& Arbib, 1982 p. 640). Few, though, have drawn the same conclusion that neurons within the brain act as a three-dimensional model of the world. The main argument suggesting otherwise focuses upon scale change, that is, every neuron is an individual and so to cover all experiences the cognitive map would have to be huge. Second, there is no allowance for an update of new data, which would effectively mean a rebuilding of each neurons identity.

Analogy: A Cognitive Map is like a map. Alternatively, an implicit argument for cognitive maps having map-like properties are the same results which discover euclidean spatial relationships within the spatial products. If the spatial products we obtain in experiments are euclidean or can be considered to be euclidean after task strategy error is removed, surely it is implied that the spatial relation knowledge held within the mind is also euclidean in nature. Kaplan (1973a, pp. 275-276) initially hypothesized this viewpoint:

It further assumes that this information is coded in a structure which people carry around in their heads, and this structure corresponds, at least, to a reasonable degree, to the environment it represents.

He continues to state that this map is far from a cartographer's map, however. It is schematic, sketchy, incomplete, distorted, and otherwise simplified and idiosyncratic' (Kaplan, 1973a, p. 276).

In effect, the analogy is that the 'map in the head' inspected by the 'mind's eye' is functionally identical to a graphical map inspected by the physical eye (Kuipers, 1982). That is, cognitive map information is isomorphic to information held in a graphical map, so that information added to, and retrieved from, the cognitive map is similar or the same as operations used to add or retrieve information from a graphical map (Kuipers, 1982). Although this does not mean that there must be a region in the brain onto which the environment is physically mapped (Stea, 1969; Kuipers 1982), but rather that there will be a correspondence between input-output behaviours of the storage and retrieval functions of the two representations (Kuipers, 1983). Statements such as 'Every person acquainted with an environment possesses a simplified cognitive structure of the environment' (Goodchild, 1974, p. 157); '...integrating information... to form an overall representation something like a survey map' (Newcombe, 1982, p. 74) and '...that give the cognitive map its maplike properties' (Garling et al., 1985, p. 147) do though imply a representation with map-like qualities.

Downs and Stea $(1973 c$, p. 11) used the term 'map' to denote a functional analogue. 'The focus of attention is on a cognitive representation which has the functions of the familiar cartographic map but not necessarily the physical properties of such a pictorial graphic model' and consequently argue it is an analogy to be used, not believed. One of the problems encountered by readers are these deceptive and misleading qualities of the analogy (Downs \& Stea, 1973c).

Metaphor: A Cognitive Map works as if it were a map. The reason for believing that the cognitive map is a metaphor is the belief that we act as if we possess a map in our minds (Kaplan, 1973a; Graham, 1976). If being used as a metaphor, the cognitive map should be interpreted, it was like he had a map in his head':

The problem is, it is easy to slip into the belief that a map is something that people have stored away somewhere in the head (Downs, 1976, p. 68).

As Spencer et al. (1989, p. 108) state:

The metaphor of a map in the head is so persuasive that we are tempted to believe that there is no metaphor, but rather that our questioning of the subject is the search for the dimensions of a real 'thing'.

This though does not mean that we do in fact possess such a map, and assuming we do, removes the metaphors heuristic value (Tuan, 1975). What makes the spatial metaphor 'map' so useful is that it:

makes the relationships explicit and because it provides the necessary guidance for using imagery to remember abstract conceptual relationships that are not easily imaged (West et al., 1985, p. 22).

The main argument against such a cognitive map construct is the non-euclidean properties discovered by some methods of investigating our knowledge structures, and the fact that we have incomplete knowledge not integrated into one single 'map' but rather disconnected components (Kuipers, 1983).

Hypothetical Construct: a convenient fiction. Cognitive maps described as hypothetical constructs render the word 'map' redundant. In this context 'map' has no literal meaning and although the term could be misinterpreted to imply that a cognitive map is a map, or is like a map, or works like a map, the implication is not intended:

As hypothetical constructs, cognitive maps have an allegedly real status; they refer to hypothesised underlying entities or processes that there is reason 
to believe do exist, which are in principle observable... . Thus, as a hypothetical construct, the term cognitive map and its approximate synonyms refer to covert, non-observed processes and organisations of elements of knowledge (Moore \& Golledge, 1976, p. 8).

The reasoning behind such arguments are spatial products with non-euclidean natures, such as intravisity (A is estimated greater than $\mathrm{B}, \mathrm{B}$ is estimated greater than $\mathrm{C}, \mathrm{C}$ is estimated greater than $\mathrm{A}$, where $\mathrm{A}, \mathrm{B}$ and $\mathrm{C}$ are interpoint distances) or non-communicavity (distance from $\mathrm{A}$ to $\mathrm{B}$, is not equal to the distance from $B$ to $A$ i.e. asymmetry), and leads to arguments of 'impossible figures' or 'spaces' (Tversky, 1981; Baird et al., 1982). Whether these hypothetical internal entities' (Newcombe, 1985, p. 277) are like, or work like, a map is immaterial; the term map is used just to represent a set of processes which are believed to exist and affect our everyday spatial behaviour. As Siegel and Cousins (1985, p. 349) state:

...cognitive maps are hypostatizations-abstractions that we create and use in understanding the sequence and development of the continual activity of cognitive mapping. In this sense, cognitive maps are a convenient fiction.

The position adopted for this paper and explained earlier, is that cognitive maps are hypothetical constructs.

Alternative expressions. This confusion concerning the meaning and context of the term has also led to the use of surrogate terms. These terms while being defined and used in some papers in a slightly different context to a cognitive map, have been used in others, instead of, or to imply 'cognitive map'. This is not aided by the fact that several authors are using the terms interchangeably across articles and in some cases within articles. Possible surrogates include abstract maps (Hernandez, 1991), cognitive configurations (Golledge, 1977), cognitive images (Lloyd, 1982), cognitive representations (Downs \& Stea, 1973b) cognitive schemata (Lee, 1968), cognitive space (Montello, 1989), cognitive systems (Canter, 1977), conceptual representations (Stea, 1969), configurational representations (Kirasic, 1991), environmental images (Lynch, 1960), mental images (Pocock, 1973), mental maps (Gould \& White, 1974) mental representations (Gale, 1982), orientating schemata (Neisser, 1976), place schemata (Axia et al., 1991), spatial representations (Allen et al., 1978), spatial schemata (Lee, 1968), topological representations (Shemyakin, 1962), topological schemata (Griffin, 1948), and world graphs (Lieblich \& Arbib, 1982).

\section{Why Are There Variations in Definitions}

Cognitive mapping's varying definitions are basically the result of its multidisciplinary nature. Cognitive mapping has no one strong subject base and is essentially a research topic with inputs from most of the social sciences. Papers and books can be found from geographers, planners and architects, psychologists, sociologists, anthropologists, political scientists, cognitive scientists and neurologists. This has advantages, giving the subject a wide base of knowledge and viewpoints, but does tend to mean that there is no strong united philosophical and theoretical base. This position has led to a variety of standpoints that currently exist. The movement towards integration (Garling \& Evans 1991; Garling \& Golledge, 1993) should help to alleviate the situation.

One additional problem noted by Allen (1985) is the fact that the term 'cognitive map' has become an all-purpose, unrestricted entity describing all behaviour and thought concerning the spatial environment. The term has no practical constraints or boundaries. As a result he (Allen, 1985) calls for the use of more rigorous constructs from the study of cognition. The position advocated here is that the term should be used in this utilitarian way to represent the knowledge of, and interactions with, the everyday environment, and geographical information gained through other secondary sources such as maps, and that a new set of terms such as Liben's (1981) 'spatial thought', 'spatial storage', and 'spatial product' should be used to represent specific concepts.

\section{Theoretical Worth: Conceptual Research}

\section{General: influences and explains behaviour}

In the early $1960 \mathrm{~s}$, the behavioral approach in geography evolved as an answer to positivism (Golledge, 1981), as researchers began to realize that to exist in, and comprehend the environment, we formed cognitive maps from the mass of 'to whom it may concern' messages emanating from the world in which we live (Golledge \& Stimson, 1987). The belief was that we could increase the explanatory powers and the understanding of geographers by incorporating behavioural variables, along with others, within a decision making framework that sought to comprehend and find reasons for overt spatial behaviour rather than describing the spatial manifestations of behaviour itself (Golledge, 1981). In effect it was an: 
attempt to base the explanation of human spatial activities on a foundation of human behavioral processes (Golledge, 1985, p. 113);

to define models of man that were alternatives to the classic models of normative economic rationality used in the past (Pocock, 1972) using data collected at the individual/micro-scale rather than using large scale governmental data (Golledge, 1985), and analysed using a series of:

methods and models tied to non-normal statistical populations, non-parametric data, non-linear distribution activities, with an interest in multidimensional spaces, as well as physical spaces (Golledge, 1985 , p. 113).

Thus the black box of man (an unknown constant in the study of environment/behaviour relationship) is replaced by a white box, in which the variable nature of man is recognized as being of fundamental importance (Downs, 1970). As Couclelis (1986) explains we have become interested in 'answers to questions such as "how do people really behave" or "how do people really make decisions".'

The general belief is that cognitive mapping explains and leads not only to the understanding of spatial behaviour, but the cognitive map is a mental construct (be it explicit, analogical, metaphorical or hypothetical) that actually influences behaviour, and by examining a whole range of spatial products (external representation of our cognitive map knowledge) we can understand spatial decision making and subsequent behaviour. Lynch (1976, p. xiii) explains that:

People's behaviour in large-scale environments can be explained more completely through recourse to internal, subjective factors than by more traditional external, "objective" factors, and that behaviour is mediated by the image (cognitive map) of the environment.

A sentiment shared by MacEachren (1992, p. 245);

The knowledge of space (cognitive maps) is critical to attitudes toward, decision making about and behaviour within places

and strongly advocated by Downs and Stea (1973c, p.10):

We are postulating the cognitive map as the basis for deciding upon and implementing any strategy of spatial behaviour... . We view cognitive mapping as basic component of human adaptation, and the cognitive map as a requisite both for human survival and for everyday environmental behaviour.

It is argued that we all have daily navigation decisions to make involving choice processes, for example, migration, shopping or recreation, which it is hypothesized are influenced by our ability to understand the everyday environment, i.e. cognitive maps (Golledge et al., 1976). As Baird et al. (1979, p. 92) point out:

The ability to plan and execute movement in a familiar environment seems to require that one possess a cognitive map [representation] of that environment in addition to the stimulus information directly available to the sensory systems.

This has led Cadwallader (1976, p. 316) to suggest that the cognitive maps affect at least three types of decisions:

(1) The decision to stay or go.

(2) The decision of where to go.

(3) The decision of which route to take.

Garling et al. (1985, p. 143) add one more decision to this list:

(4) The decision of how to get there.

One of a cognitive map's functions then is to rehearse spatial behaviour in the mind so that when we are actually travelling, we can act with a degree of assurance that we would otherwise not have (Tuan, 1975). They are in effect advanced organizers that influence the impact of later direct experience of the environment (Liben, 1991).

The arguments concerning cognitive maps and spatial behaviour are circular though, and although 'our knowledge of the external world impinges upon our actions...our acts affect our knowledge' (Webber et al., 1975, p. 100). This suggests that our cognitive maps are not stable entities, but are dynamic: constantly changing and evolving. We are constantly learning and altering the information we use to make spatial decisions. 'Behaviour modifies and is modified by interaction with the spatial environment' (Matthews, 1980, p. 178).

Boyle and Robinson (1979) have expressed doubts as to what a cognitive map is, and define it as a figural image with a cartographic form, in a sense an analogy. Upon this basis they argue that cognitive maps have a use in explaining human behaviour but conclude that 'cognitive maps play only a minor and intermittent role in effective thinking and that it is misleading to impute to them any great significance in the co-ordination of our spatial activities' (Boyle \& Robinson, 1979, p. 64).

A more effective argument against the utility of cognitive maps in explaining spatial behaviour has been argued by Piaget \& Inhelder (1956) who state that behaviour in space and representation of space are in fact very different and they make the distinction between 'practical' space (the capacity to act in 
space) and 'conceptual' space (the capacity to represent space. The capacity to act and move intelligently through space may well occur before, and possibly in the absence of, the capacity to represent that space (Spencer et al., 1989). This argument is accepted, but it is argued that the subject still possesses cognitive map knowledge, which they find difficult to represent externally.

Research concerning spatial behaviour within the environment can be divided into three main strands of spatial problem solving: spatial decision making (whether, why and where questions), wayfinding (how questions) and development of acquisition and learning (what and when questions).

\section{Spatial problem solving: spatial choice and spatial decision making}

It is hypothesized that the cognitive map provides information necessary for spatial decision making and to execute the consequent behaviour (Briggs, 1973). The cognitive map as discussed, therefore plays a role in four vital questions: whether to go somewhere; why go there; where it is that is the destination; and how to get there. Researchers have investigated these questions from the perspective of cognitive mapping in relation to a series of application areas: consumer behaviour (Coshall, 1985a,b); residential and business location (Pacione, 1978, 1982); movement patterns within an urban area (Johnston, 1972; Briggs, 1973) and recreational and leisure destinations (Golledge \& Timmermans, 1990).

These all have real world applications, concerning planning, teaching and advertising. These are discussed later, but the general argument is that if we can understand where people want to go and why, then planners both governmental and commercial can plan for their needs. Another application could be advertising. For example, it is now noticeable within the marketing of business parks the use of centrality and ease of access as factors that sell. If you can alter peoples cognition of distance you could attract more custom. Studies that have looked at cognitive mapping in relation to spatial decision making though, tend to only take theory and investigate its worth, without then re-contributing to theory making.

\section{Spatial problem solving : wayfinding and spatial orientation}

Wayfinding is the ability to learn and remember a route through the environment (Blades, 1991) with the overall goal being able to relocate from one place to another in large-scale space (Gluck, 1991). Spatial orientation refers to the process by which a person knows where he or she is relative to something else (Garling \& Golledge, 1989). These both use high level cognitive processes and are different from kinaesthetic senses of orientation and wayfinding which are low level reflexes for maintaining equilibrium (Gluck, 1991).

Gluck (1991) has divided up wayfinding research into two main categories: Competence and Performance literature. Both can be split into two further categories. The competence literature subdivided into computational models and information processing models, both of which can be interpreted as acquisition and learning models. These are often still implicitly or explicitly based in the theoretical frameworks of environmental cognition. The performance literature can be divided between general studies (applicable across all groups) and specific studies (children, elderly, special needs).

Computational models of wayfinding are the result of the continuing expansion of artificial intelligence to research in the social sciences. There are two main model types: cognitively based and biologically (connectivist) based. The cognitively based models are centred around memory structures and information processing and the biologically based around the behaviour of neurons and are often referred to as parallel distributive process models (PDP) (Golledge \& Timmermans, 1990). A further distinction in artificial intelligence is made between 'scruffies' and 'neats' (Zimring \& Gross, 1991). The 'scruffies' primary focus is on producing a computational model where the outcomes mimic human behaviour and in general are searching for direct links between the environment and behaviour. 'Neats' are interested in reproducing human outcomes, but adopt cognitive science approaches that attempt to model people's mental processes accurately as well (Zimring \& Gross, 1991). It is generally the case that biological models are scruffy, whereas cognitive models are neat.

Most popular among social scientists are cognitively based models. These models attempt to simulate human mental processes with computer programs (Kuipers, 1982) with the belief that an individuals permanent knowledge structure provides the basis for interpreting objects, actions and events in the external environment' (Smith et al., 1982 , p. 307). In general, they attempt to simulate a wayfinder that learns the paths and landmarks in a large-scale space, and then can navigate through the space it knows, solving route-planning tasks. Models are often distinguished in terms of how the 
environment is represented, and to the extent to which the knowledge is seen as procedural, topological, or metric (Golledge 1992). The aim is to determine the types of knowledge that exist, the manner in which such knowledge is represented and organized, the mechanisms by which it is activated, and the elementary and higher level cognitive processes that operate upon the knowledge base to produce new knowledge, inferences, evaluations and external behaviours' (Smith et al., 1982, p. 307). In other words to discover how we store, think about and carry out wayfinding activities. It is though not intended to replace theory but add to its development (Garling \& Golledge, 1989).

Example cognitive programs include, TOUR (Kuipers, 1978); TRAVELLER (Leiser \& Zilbershatz, 1989) ELMER (McCalla et al., 1982); SPAM (McDermott \& Davis, 1983); MERCATOR (Davis, 1983); CRITTER (Kuipers, 1985); NX Robot (Kuipers \& Levitt, 1988); and Qualnav (Levitt et al., 1987, 1988). NAVIGATOR (Gopal et al., 1989) combines elements from spatial cognition and neurologically based information processing. Application studies includes Golledge et al. (1985) on wayfinding of children in a suburban area, an Couclelis's (1986) navigation in an airport.

Information Processing models are the second category proposed by Gluck (1991) These are effectively non-computational process models of how and why we acquire and learn the everyday environment, including routes for wayfinding. Much of the work in this area has been carried out by the Environmental Psychology Research Group at the University of Umea, Sweden (Garling et al., 1981, 1985, 1986; Saisa et al., 1986) concerning the use of travel plans to link cognitive map information processing with actual behaviour. These travel plans are in essence action plans, and are predetermined courses of action to reach a desire destination with the minimum investment of effort.

The Performance Literature is concerned with the actual collecting and assessment of data rather than the building of acquisition and learning theories. It focuses on problems of measurement, discussing how to collect distance, direction or locational estimates to assess the route knowledge individuals possess for wayfinding. The aims of this research is to find factors that affect the cognitive map, thus route knowledge and hence wayfinding, and then to integrate the results into existing theory. The number of factors are huge, ranging from personal characteristics, traits, meaning and ability; perceptual context; environmental influences to social influences.
This is often looked at the general scale where results are considered applicable to all types of subgroups of people. Some studies though concentrate at the more specific level concerning the wayfinding and orientation of specific subgroups of the population such as children (see work by Blades \& Spencer), the elderly (see work by Ohta; Kirasic) and those with special needs be it mental or physical (see work by Spencer \& Blades; Golledge et al., 1979, 1983).

\section{Spatial problem solving: acquisition and learning}

The previous section dealt with wayfinding and discussed two types of investigation that looked at the acquisition and development of wayfinding and orientating skills. This section discusses cognitive map development as a whole, and why this research is important at a academic, intellectual level and the implications for both theoretical and applied research.

Research in this area has been traditionally been dominated by psychologists particularly those of developmental persuasion (Spencer \& Blades, 1985), and can be split into three competing philosophical traditions which attempt to explain the development of cognitive mapping (Matthews 1992). These can be neatly represented by three questions (Table 1).

From a purely academic standpoint the study of development and acquisition is vital to our understanding of how a cognitive map is composed, constructed and organized, and when changes occur in the development of this knowledge (Hazen et al., 1978). Such studies are 'admirable because they portray an unfolding process' (Lynch, 1976, p. v) and essentially form the basic cornerstone in the understanding of mature forms of understanding an experience' (Moore, 1976, p. 138). The implications of this research are therefore fundamental in the development of models of spatial behaviour and in practical applications such a teaching and planning

TABLE 1

Philosophical traditions of development research

1 Is cognitive mapping ability given innately, and closely aligned to language acquisition (nativism)?

2 Is cognitive mapping ability built up empirically from sensations derived from experiences of different geographical environments (empiricism)?

3 Is cognitive mapping ability constructed out of some sort of interaction between inherited and experiential factors (constructivism)?

Source: Matthews (1992, p. 69). 
because it reveals what knowledge people know and when this knowledge can be expected to develop.

\section{Mnemonic and metaphorical devise}

Tuan (1975) suggests that one of the functions of a cognitive map is as a mnemonic devise. They are important because if "we wish to memorize events, people, and things, it helps to know their locations or even assign them arbitrary locations' (Tuan, 1975, p. 210). Cognitive maps are therefore a means to structure and store knowledge (Saarinen et al., 1988). Gilmartin (1985) has suggested that the visualization component (the images we can form on the 'mind's eye') has been used for thousands of years to enhance the learning and recall of information and Bellazza (1983, p. 830) describes such visualization as the 'oldest known mnemonic devise'. West et al. (1985) explain that this involves imagining to-be remembered items in locations in a familiar environment, and then remembering the items by taking a 'mental' walk through that environment. Spatial thinking is often used as a metaphor for non-spatial tasks, where people performing non-spatial tasks involving memory, imagery and inference use spatial knowledge to aid processing the task (Downs, 1985).

\section{Local/world attitudes and perspectives}

The cognitive map as explained earlier extends beyond knowledge of spatial relations to contain social and environmental meaning knowledge. This information is used to shape our attitudes towards, and perspectives of, the world, and hence our behaviour patterns at the local and national level. This, Golledge \& Timmermans (1990) hypothesize manifests itself in everything from public reactions to events, to individual decision making as reflected in tourism and investment. These attitudes are more than just 'ignorance surfaces' as discussed by Gould (1983) but rather models on which people make everyday decisions. Obviously studies which reveal how we think about 'places' can give us insights into how 'we' are cognized and how we cognize other areas, and clues as to how to change our 'image' to create a more favourable one. As pointed out by Saarinen (1973, p. 148):

It seems important in a world continually upset by international conflicts to try and gain an understanding of variations in world views.

The underlying belief is that when current world 'images' are understood, education can be designed to remedy any weaknesses revealed, thereby provid- ing a basis for improved international understanding (Walmsley et al., 1990). Saarinen and his assistant MacCabe have been investigating the world 'images' of students (3863) from all over the world (49 countries) as part of a large scale study (see Saarinen, 1988; Saarinen et al., 1988, 1992) Studies of cognitive mapping reveal how we do think about places, and certain studies show the connection between attitudes and planning, such as Gould (1969), Banerjee \& Lynch (1977) and Lynch (1977).

\section{Creating and coping with imaginary worlds}

Tuan (1975) has hypothesized that cognitive maps also act as imaginary worlds. They depict attractive goals that tempt people out of their habitual rounds. We can as human beings construct mental descriptions of places we have never been to, from text such as a novel or word of mouth, such as a friend's description of a holiday area. What we essentially do is fit them into our schema of similar events we have experienced either first hand or secondhand through the media. In this way our cognitive map schemata allow us to create and cope with unknown place information. This may have practical relevance to studies of our attitudes towards places as discussed above, or to historical geography in explaining why people migrated to certain destinations (Tuan, 1975).

\section{Applied Worth: Instrumental Research}

\section{Understanding cognitive maps for geographers and urban planners}

General. The general implicit belief, especially amongst geographers (Aitken, Downs, Golledge, Gold, Humphreys, Pocock, MacEachren) and planners (Appleyard, Lynch, Moore, Okabe) is that:

knowledge gained about perceptual-cognitive processes may improve the quality of human environments through policy, planning, and design, to the extent that it tells us how to plan and design environments that do not interfere with the proper functioning of these processes (Garling \& Golledge, 1989, p. 203).

Lynch (1976, p. xi) clarifies this by stating:

...[we] can better plan, design and manage the environment for and with people if we know how they image the world.

In effect, there is increasing evidence that environment and behaviour are interdependent (Lee, 1968), so that environments can influence behaviour, and 
explanations of behaviour can be used to influence the make-up of environments. Indeed Golledge and Timmermans (1990, p. 76) report that:

specific applications of the models and knowledge gained from investigations of cognitive mapping and the acquisition of spatial knowledge are occurring with increasing frequency in environmental design, architecture and planning.

The challenge then is to provide both information about how people experience the physical environment, and the sorts of human needs that the physical environment must satisfy, to planners relatively starved of detailed behavioural data, so that there is adequate planning in the built environment that reflects the behavioral propensity of residents and other users (Kaplan, 1973a; Aitken et al., 1989). This has resulted due to pressure on public decisionmakers to provide structures and facilities which are useful and acceptable to their intended users (Lowery, 1973). By studying the spatial products of the cognitive map, such data will hopefully become available, rather than designers relying on intuition, rule-of-thumb and details from past work, to decide on what places of the future will look like (Kaplan, 1973a, Downing, 1992).

If cognitive mapping can be used to improve environmental design then this should be explored. Canter (1977) has preliminarily examined the idea of encorporating cognitive mapping into design, but there has been little conceptualization of guidelines or policy. A fact of which Siedel (1985) is critical. The implication of this are discussed later.

Examples of where policy has been suggested include Golledge et al.'s (1979, 1983) investigation of policy guidelines needed to allow the mentally retarded a full and active use of their local environments. Carpmen et al. (1985) explored the effects of hospital design upon wayfinding, and found that poor design caused increased environmental stress to staff, patients and visitors. They suggest that this could be avoided through the introduction of a policy of clear maps, directories, you-are-here maps at key decision points, as well as trained staff able to give clear and concise directions.

Passini (1992) has also examined wayfinding and the role of planners and designers in environmental design. He presents a guideline design method, which conceptualizes wayfinding as a spatial-problem solving process. There are seven steps, the first four area analytical, and the last three are aimed at stimulating reflection to arrive at a design solution.

Seelig and Seelig (1986) have noted that it must be made clear that other types of knowledge must
TABLE 2

Reasons for planning for children

1 Children and adults differ in behaviour patterns, with play and education having a major role for children.

2 Their land uses and facilities differ; or, where shared, are often used for different purposes.

3 Daily ranging patterns differ, in ways that reflect adult's greater autonomy and access to resources.

4 Children face different (and possibly greater) threats from their environment.

5 Children are entirely outside the politico-economic decision-making process that determines land-use; adults have a greater chance of participating

6 Children and adults differ in their interpretation of plans.

Source: Spencer et al. (1989, p. 223).

be included in the design process (including cognitive mapping knowledge) beyond analytical, objective knowledge. As Goldberg (1983, p. 24) states:

subjective and value laden intuitive knowledge merit equal credibility as sources of planning know-how. Experientially rooted synthetic knowledge is an essential complement to the deductive analytical information base of the present.

Children's environments. Can research concerning cognitive mapping provide us with information concerning the environmental needs of children? The previous section suggests that they can. If they can, why should we want to plan environments for children? (Hill and Michelson (1981) have offered some reasons (Table 2).

These points mean that children and adults cognize and use the environment in different ways for different means. If how children cognize the environment affects their behaviour, activity patterns and interaction environment, research into how children do cognize the environment could be valuable to both sociologists and architectural planners, with a view to creating environments more suited to children's needs, and may go someway to help alleviate the growing youth social problem. One study that has tried to do this was an international project sponsored by UNESCO, and carried out in Mexico, Poland, Australia and Argentina (Lynch 1977). This research focused on low-income, lowresource areas of cities, and was intended to suggest public policy for neighbourhood improvement.

Elderly environments. The elderly have been studied by a small number of researchers (Ohta, 1983; Ohta \& Kirasic, 1983; Regnier, 1983 Kirasic, 1985, 1989, 1991; Kirasic et al., 1992) interested in how the elderly learn new environments. It is 
hypothesized that age-related decrements in the ability to learn and wayfind in an environment could have a impact on the quality of life for elderly adults (Gold \& Goodey, 1987; Kirasic et al., 1992). As Kirasic states (1985, p. 185):

It is ...imperative that we understand the nature of any spatial cognitive changes that occur with the increasing of age because any age related decline in spatial abilities should have a clear and significant impact on the elderly's individual's transactions with his or her spatial environment.

A possible solution to this would be to discover the type of environments the elderly map cognitively, and hence can learn most quickly. These 'optimum' environments may be more suitable as a living area, and as such should be useful to planners creating places used predominantly by elderly people, such as residential homes and hospitals (Axia et al., 1991). They should not, however, disregard environmental features that appeal to the elderly's environmental assessment, but should contain a mix of easy to remember and pleasing features. It is also important that they contain features of practical importance, such as needed resources (shops and services) (Regnier, 1983).

Environments for special needs people (both physically and mentally handicapped). People with special needs often come to know the environment in different ways to the fully-abled. For some, interaction may be hampered due to some type of physical or mental handicaps, meaning fewer and lessactive participation with their surroundings. Others might suffer from less interaction due to impaired perceptual development or loss-most commonly blindness (Spencer et al., 1989). The need for research into how these section of society form and use cognitive maps is vital to the planner and educationalist if we are going to be able to maximize their interaction and enjoyment of everyday environments.

Fears are based around the notion that an immobile child will become an immobile adult, suffering dependency problems which could lead to psychosocial and adjustment problems (Spencer et al., 1989). The aim is to improve the life style of these groups to the point where they can 'travel safely, comfortably, gracefully and independently' (Foulke, 1983). For this to be realized individuals have to possess basic cognitive maps, that is they have to know where they are, where their goal is, and how to get between them. This requires that motor, perceptual and representational skills are attained by the traveller (Spencer $e t$ $a l .$, 1989) and cognitive map knowledge built.
The arguments run circular so that, we need suitable environments for special needs groups to operate in, and cognitive mapping research tells us whether such environments exist and point clues as to how to improve them. Golledge et al. $(1979,1983)$ have studied the cognitive maps of mentally retarded subjects with the aim of understanding how they cognize the environment they operate, so that guidelines could be provided for enhancing the environmental behaviour competence, and to discover which elements of the environment facilitated and impeded their use. Such information has dual purposes of enhancing education and providing details to planners.

\section{Understanding cognitive maps for education and computer interfaces}

Geographical education: general. Children's cognitive mapping research has been and continues to be studied for the purpose of improving education (Catling, 1979; Matthews, 1980, 1992). There are two hypotheses. First, it is believed that the spatial products reveal clues as to the level of geographical development of individuals, and provide us with information which we can use to improve education, increasing the range of spatial stimuli and elicit more suitable techniques of teaching (Hart \& Moore, 1973). Second, that cognitive mapping exercise could be used as a means of enhancing the child's personal geography and as such is a way of enriching the teaching of geography, especially at the personal level (Catling, 1978a,b, 1979). The approach advocated is that children examine their own and their peer's cognitive maps to learn about their experiences with the environment, with the aim of increasing awareness of places, details, and patterns in the neighbourhood (Spencer et al., 1989) and to introduce a number of aspects of map work and geographical and environmental studies (Catling 1978b). Such thoughts have provoked a number of researchers to argue for environmental education becoming central to the contemporary curriculum (Goodey \& Gold, 1985; Matthews; 1986).

As Hart \& Moore (1973, p. 283) point out:

Geographic education has only recently begun to take note of the crucial importance of considering the development of the child's conception of space.

Beyond the confines of a classroom and academic learning, Brewster and Blades (1989) have found that both children and adults can be taught how to improve their cognitive maps, and to operate in an enviro nment more efficiently, thus leading to 
greater environmental awareness and ability. A reason for study noted by Pocock (1980). This finding has yet to be carried into the classroom, where the lack of studies mean that evaluation of the impact of such teaching make it difficult to assess. Do children performing such exercises gain a better environmental awareness, greater graphicacy and locational skills to those that are not? (Spencer et al., 1989).

Geographical education: concern for gender differences. Another area of concern focuses upon gender abilities of boys and girls to perform to the same level at geographical problem solving tasks. Saarinen et al. (1988) have noted that females consistently performed below males on the NCGE Geographic Competency Test and in their sketch map experiments. Other researchers have noted similar such differences (Kail et al., 1980; Jahoda, 1979; Moore, 1979; Brown \& Broadway, 1981; Spencer \& Weetman, 1981; Gilmartin, 1984; Matthews, 1986; Brewster \& Blades, 1989; Downs \& Liben, 1991) but others have found none or expressed reservations and unhappiness with the findings (Feldman \& Acredolo, 1979; Liben \& Golbeck, 1980; Gilmartin \& Patton, 1984; Webley \& Whalley, 1986; Allen, 1988; Garling, 1989; Blades, 1990; Self et al., 1992). The reasons for this are a contentious issue and a large debate is currently in progress centring around the spatial ability literature (for possible reasons see Table 3 ).

Obviously if such differences actually exist, we need to determine the reasons, so that we have the opportunity to alter our curriculum to readdress the balance. As noted earlier cognitive mapping and spatial ability influence other subjects beyond geography and the ability to navigate within the environment both of which are important issues. If the reason is due to social roles and stereotypes

TABLE 3

Possible reasons for differences between male and female spatial products

1 Males and females having different ways of approaching the same problem, using different cognitive strategies.

2 Performance and behaviour indicators favouring boys.

3 Males and females possess different cognitive maps and information.

4 Males and females are taught differently, and attending different courses.

5 Females positively react to stereotypes.

6 Females have different social role constraints limiting their opportunities for environmental experience.

7 Males and females have biological differences affecting the ability to understand and perform the task. research can be used to provide evidence for this social justice issue.

Geographical education: cartography and remote sensing. It is believed that cognitive mapping (Thorndyke, 1981; MacEachren, 1991) and associated spatial abilities (Self et al., 1992) could have an effect on more technical aspects of geography including cartography, remote sensing and GIS (discussed next section). There are two ways to approach the problem, which are interrelated. First, you can try and discover how we cognize and use cartographic maps with a view to improving spatiovisualization skills and general understanding and comprehension of spatial relations. The second method is by improving cartographic based material to make learning easier (see next section). Both involve the use of cognitive mapping skills.

Research concerning how we cognize and use cartographic maps with a view to improving spatiovisual and geographical understanding focuses around two central research themes. The first is concerns how we literally perceive the map and integrate this knowledge into the cognitive map, with the aim of teaching these skills more effectively. Much of this work focuses around improving map reading and interpretation skills, and spatial ability (Thorndyke \& Statz, 1979; Gilmartin \& Patton, 1984).

The second concerns how we use other geographical knowledge in understanding the map. As Golledge et al. (1992) notes one of the unanswered questions is how do we convert travel experiences upon which we base much of our understanding of space and spatial properties into comprehension of simple spatial processes such as nearest neighbour, distance decay, regionalization and others fundamental for comprehending maps and diagrams and interpreting them for use in human activity (Golledge et al., 1992)? Such research is necessary if we are to improve cartographic based education and open up such areas to naive users.

I do not know of any research that specifically investigates the utility of remote sensing to improving geographical education although a few investigators have looked at effect of gathering spatial products through aerial photography recognition Stea \& Blaut, 1973; Matthews, 1984).

Improving cartography and remote sensing. By investigating ways in which we currently integrate map information into the cognitive map, and how this information is subsequently used in navigation and to interpret other maps it is hoped we can learn 
how to improve cognitive map ability and the maps. As Lloyd (1989, p. 109) points out:

Cartographers hoping to provide better maps for people to read should understand the cognitive processes used to read maps.

Researchers such as Thorndyke and Hayes-Roth (1982), and MacEachren (1991) have argued that there needs to be an interface between human perception and cognition and the graphic characteristics of a map. Thorndyke (1981) has suggested that how we judge distances can be affected by our use of maps and that clutter on maps leads to overestimation of distances. He suggests that we should consider presenting geographical displays that supply requested information but minimize the amount of attendant, irrelevant data (Thorndyke 1981). By understanding which elements of maps distort our cognitive maps it is hoped we can improve the map, in this case by removing unnecessary clutter. There are other factors which influence the cognitive map such as the map projection used (Gilmartin \& Lloyd, 1991). The solution to this is to produce maps applicable to specific needs only, maybe a role of GIS in the future. MacEachren (1991, p. 161) sums up neatly by stating:

Considering how people learn about space and how they deal with the spatial aspects of their environment on a daily basis will allow us to devise maps, and map presentation strategies, that facilitate thinking and problem solving rather than memorising.

The same argument could be used to improve remote sensing, a situation noted by Edwards (1991). He has discussed how the cognitive map may be a vital base upon which our inferences concerning remote sensing data are based. In such cases we convert the images into two-dimensional base maps, by utilizing our perceptual systems in conjunction with our cognitive maps to identifying regions with similar spectral and textual properties, the relationships between these regions and neighbours, and knowledge about the physical connections between scene elements (Edwards 1991). If we understand how we cognize such images (most of which are false-colour composites) we could try to improve them to increase user understanding.

Improving computer interfaces and databases focusing upon GIS. GISs and cognitive maps share similar purposes. GISs being systems designed to process data concerning the everyday geographical environment, and cognitive mapping concerning how we think, store, produce and utilize such data. Both contain data concerning spatial relationships
TABLE 4

Applications of cognitive maps to GIS

1 Cognitive map information could be used to supply designers with knowledge that could improve system's interface, and thus make them easier to use.

2 Cognitive map information concerning how we store and think about geographical data could be useful in improving database design and efficiency.

3 Cognitive map information could be used to improve education, specifically to increase understanding of the images displayed (discussed in the previous section).

and attributive data assigned to specific places in a space-time framework. Work though into the possible connections has been confined to the application of spatial cognition to GIS, and a handful of investigations utilizing GIS for behavioural studies. Concentrating on the application of cognitive maps to GIS it hypothesized that cognitive maps could be of importance in three main ways (see Table 4).

GIS suffers from two basic interface problems that cognitive mapping research could be useful in rectifying: unfriendliness reducing potential benefits and misinterpretation leading to misuse. These problems need to be addressed if GIS is to succeed.

Medyckyj-Scott et al. (1990) have noted that the increased sophistication of GIS has not always been accompanied by an improvement in usability, because GIS makes considerable demands on its users. The enlarged functionality makes the GIS increasingly complex and daunting, especially if interfaced in a non-intuitive way, and leads to focusing upon a small number of specific tasks reducing the exploitation of potential benefits (Medyckyj-Scott \& Blades, 1992). The utility of the GIS is being undermined. As Mark and Gould (1991, p. 1428) state:

When the user sits at a workstation and uses a GIS, he or she should be thinking about real-world phenomena, and not about computers or peripherals, commands or syntax, layers or pixels.

The second problem of misuse through misinterpretation often stems from the first. Where efforts have been made to improve usability, the ease of use, coupled with a lack of appreciation of the complexities of spatial data, has led to the employment of the wrong data types, at the wrong scale/resolution, and in the wrong context to produce erroneous results and conclusions (Medyckyj-Scott \& Blades, 1992).

There are two ways to tackle this problem. The first expects the user to adapt to the system by learning about space in the systems terms, acquiring a set of data structure-based concepts and the 
accompanying vocabulary (Gould, 1991). The second involves the GIS design to be centred upon how people think and utilize everyday geographical space, i.e. based upon people's cognitive map knowledge. A view adopted by Mark (1989, p. 551) who asserts:

Optimal GIS interfaces will be based on the same cognitive maps [image-schemata] that are used when the person involved interacts directly with the realworld phenomena represented in the GIS.

The first method of learning is impractical both in terms of time and resources. As such it is rejected, and the second approach of adaptation is advocated. In this approach adaptive interfaces are proposed, that operate at a level suitable to the user. Ideally (but probably not practically for a number of years) they should not only be 'user-friendly' but 'userintimate', changing its approach to suit the particular operator's current needs (Turk, 1990). There are three prototype systems based upon this idea of adaptation: HyperArc; CUBRICON and ArcView. The first two work on the principle of trying to connect the package to the users view of the problem, and the third on the idea of reduced functionality, in effect creating a non-expert GIS.

Cognitive maps may also aid the use of interfaces by allowing them to become more easily remembered. This is because how we interface the GIS can be thought of as an analogy to wayfinding, and in the same way we use cognitive maps to facilitate movement in the environment we can build up and use conceptual models of the how to manoeuvre within the GIS. Just as when we are not familiar with a region we stick to safe, known routes, the user will do so with the GIS, and as such fail to explore the system (Turk, 1990; Medyckyj-Scott \& Blades, 1992). In essence we form cognitive maps of the system, where certain screens are linked to meaning and the understanding of actions. In this way cognitive maps act as mnemonic devices as discussed by Tuan (1975). If these cognitive maps can be improved so will user efficiency.

An understanding of cognitive maps may also improve database design and efficency. The brain is probably the most efficient user of data known to man, and an implicit argument based upon such a statement is that, if we can start to understand its structure and contents we can produce more efficient databases, both in terms of storage capacity and speed. If we can start to unravel the complexities of the cognitive map, and determine its structure the implicit argument is we can design better GIS databases. The prototype systems mentioned above are merely scratching the surface of a potential revolution in how computers may be designed and used in the future.

\section{Other Applied Uses}

David Canter has used cognitive mapping theory in tracking down criminals for the police (Canter \& Larkin, 1993; Canter \& Gregory, in press, Bouquet, 1994). He suggests that criminals' cognitive maps shape and constrain the criminal and non-criminal spatial activity of any offender (Canter \& Gregory, in press). First-time offenders commit crimes in areas where they have good cognitive maps, usually their local neighbourhood and as they get more experienced they will stray further afield. Because criminals on the whole are domicentric (reside in one location) and value familiarity with an area over the risks of being recognized (although there is a minimum distance of travel), by plotting the sites of the attacks their home location can be determined ( $91 \%$ of criminals had circular ranges) (Canter \& Larkin, 1993). Using this as a basis coupled with a criminal profile, a rapist and murderer, John Duffy, was tracked down to Cricklewood, in north-west London.

Another possibility for an applied use, may be in search and rescue operations. Certain cognitive mapping characteristics could in theory be profiled onto victims who are lost, through the descriptions of relatives and friends. This may give a detailed portrait of the victim revealing how they might behave, what type of strategy they are likely to use in trying to find their way again, and even how far they might have strayed. This may make the searchers job easier by suggesting where might be an appropriate place to look for the victim, rather than conducting large random or systematic searches.

\section{Conclusion}

This paper has broadly outlined what cognitive maps and mapping are, the reasons for misunderstandings and their theoretical and applied worth. It has been demonstrated that cognitive mapping has a role to play in spatial behaviour, spatial decision making, learning and acquisition theory making and in real world applications, such as planning, teaching, map making and computer interfaces and databases. What should be made clear though is that conceptual research is considerably more developed and actively practised than applied research. There are three main reasons for this (see Table 5).

In an age where it is increasingly difficult to 
TABLE 5

Reasons for more conceptual research

1 The (seemingly) lack of potential clients (Lynch 1976).

2 Little attempt to put conclusions into guidelines accessible to potential users (Siedel 1985).

3 Very few specific direct pieces of applied work in the past (Moore 1979).

attract grants and funding (especially in the U.K.) for cognitive mapping research to develop and take place, it has to attempt to practise applied research, formulate guidelines, and attract and make potential clients. This paper aimed to highlight the many current and potential applications, to justify cognitive mapping research, and to encourage more multidisciplinary research, especially that of an applied nature. The way forward in cognitive mapping is further integration of conceptual research and continued diversification and practice of applied research.

\section{References}

Aitken, S. C., Cutter, S. L., Foote, K. E. \& Sell, J. L. (1989). Environmental perception and behavioral geography. In $\mathrm{C}$. Wilmott \& G. Gaille, Eds., Geography in America, London: Merril, pp. 218--238.

Allen, G. (1985). Strengthening weak links in the study of the development of macrospatial cognition. In R. Cohen, Eds., The Development of Spatial Cognition. Hillsdale, NJ: Erlbaum Lawerence, pp. 301-321.

Allen, G., Siegel, A. W. \& Rosinski, R. R. (1978). The role of perceptual context in structuring spatial knowledge. Journal of Experimental Psychology: Human learning and Memory, 4, 617-630.

Allen, G. L. (1988). The acquisition of spatial knowledge under conditions of temprospatial discontinuity. Psychological Research, 50, 183-190.

Axia, G., Peron, E. M. \& Baroni, M. R. (1991). Environmental assessment across the life span. In T. Garling \& G. W. Evans, Eds., Environment, Cognition and Action-An Integrated Approach. New York, NY: Oxford University Press, pp. 221-244.

Baird, J. C., Merrill, A. A. \& Tannenbaum, J. (1979). Studies of the cognitive representation of spatial relations II: a familiar environment. Journal of Experimental Psychology, 108(1), 92-98.

Baird, J. C., Wagner, M. \& Noma, E. (1982). Impossible cognitive spaces. Geographical Analysis, 14, 204-216.

Banerjee, T. \& Lynch, K. (1977). On people and places: a comparative study of the spatial environment of adolescents. Town Planning Review, 48, 105-115.

Bellazza, F. S. (1983). The spatial arrangement mnemonic. Journal of Educational Psychology, 75, 830-837.

Blades, M. (1990). The reliability of data collected from sketch maps. Journal of Environmental Psychology, 10, 327-339.

Blades, M. (1991). Wayfinding theory and research: the need for a new approach. In D. M. Mark \& A. U. Frank, Eds., Cognitive and linguistic aspects of geographic space. Kluwer Academic Publishers, pp. 137-165.
Bouquet, T. (1994) Professor Canter: policing's secret weapon. Reader's Digest, 144(862), 45-50.

Boyle, M. J. \& Robinson, M. E. (1979). Cognitive mapping and understanding. In D. T. Herbert \& R. J. Johnston, Eds., Geography and the urban environment: progress in research and applications. London: Wiley, Vol. 2, 59-82.

Brewster, S. \& Blades, M. (1989). Which way to go? Childrens ability to give directions in the environment and from maps. Environmental Education and Information, 8(3), 141-156

Briggs, R. (1973). Urban distance cognition. In R. M. Downs \& D. Stea, Eds., Image and Environment, Chicago, Illinois: Aldine, pp. 361-388.

Brown, M. A. \& Broadway. M. J. (1981). The cognitive maps of adolescents: confusion about inter-town distance. Professional Geographer, 33(3), 315-325.

Buttenfield, B. P. (1986). Comparing distortion on sketch maps and MDS configurations, Professional Geographer, 38(3), 238-246.

Cadwallader, M. T. (1976). Cognitive distance in intraurban space. In G. T. Moore \& R. G. Golledge, Eds., Environmental Knowing. Stroudsberg, PA: Dowden, Hutchinson \& Ross, pp. 316-324.

Canter, D. (1977). The psychology of place. London: Architectural Press.

Canter, D. \& Larkin, P. (1993) The environmental range of serial rapists. Journal of Environmental Psychology, 13, 63-69.

Canter, D. \& Gregory, A. (In press). Identifying the residential location of rapists. Journal of the Forensic Science Society.

Carpman, J., Grant, M. \& Simmons, D. (1985). Hospital design and wayfinding: a video simulation study. Environment and Behaviour, 17(3), 296-314.

Catling, S. (1978a). Cognitive mapping and children. Bulletin of Environmental Education, 91, 19.

Catling, S. (1978b). Cognitive mapping exercises as a primary geographical experiences. Teaching Geography, 3 120-123.

Catling, S. J. (1979). Maps and cognitive maps: the young childs perception. Geography, 64, 288-296.

Cohen, R. (1985). What's so special about spatial cognition. In R. Cohen, Ed., The Development of Spatial Cognition. Hillsdale, NJ: Erlbaum Lawerence, pp. 1-12.

Coshall, J. T. (1985a). Urban consumer's cognitions of distance. Geografiska Annaler, 67B, 107-119.

Coshall, J. T. (1985b). The form of micro-spatial consumer cognition and its congruence with search behaviour. Tijdschrift Voor Economische En Social Geografie, 76(5), 345-355.

Couclelis, H. (1986). Artificial intelligence in geography: conjectures on the shape of things to come. Professional Geographer, 38(1), 1-11.

Davis, E. (1983). The Mercator representation of spatial knowledge. Proceedings of the Eighth International Joint Conference on Artificial Intelligence, (IJCAI 83). Karlsruhe, W. Germany, pp. 295-301.

Downing, F. (1992). Image banks-dialogues between the past and the future. Environment and Behaviour, 24(4), 441-470.

Downs, R. M. (1970). Geographic space perception: past approaches and future prospects. Progress in Geography, 2, 65-108.

Downs, R. M. (1976). Cognitive mapping and information processing: a commentary. In G. T. Moore \& R. G Golledge, Eds., Environmental Knowing, Stroudsburg, PA: Dowden, Hutchinson and Ross, pp. 67-70.

Downs, R. M. (1981). Maps and metaphors. Professional Geographer, 33(3), 287-293.

Downs, R. M. (1985). The representation of space; its development in children and in cartography. In R. Cohen, Ed., The 
development of spatial cognition. Hillsdale, NJ: Erlbaum Lawerence, pp. 323-345.

Downs, R. M. \& Liben, L. S. (1991). The development of expertise in geography: a cognitive-developmental approach to geographic education. Annals of the Association of American Geographers, 81(2), 304-327.

Downs, R. M. \& Stea, D. (1973a) Theory. In R. M. Downs \& D. Stea, Eds., Image and Environment. Chicago, IL: Aldine, pp. 1-7.

Downs, R. M. \& Stea, D. (1973b). Cognitive representations. In R. M. Downs \& D. Stea, Eds., Image and Environment, Chicago, IL: Aldine, pp 79-86.

Downs, R. M. \& Stea, D. (1973c). Cognitive maps and spatial behaviour: process and products. In R. M. Downs \& D. Stea, Eds., Image and Environment. Chicago, IL: Aldine, pp. 8-26.

Edwards, G. (1991). Spatial knowledge for image understanding. In D. M. Mark \& A. U. Frank, Eds., Cognitive and Linguistic Aspects of Geographic Space. Kluwer Academic Publishers, pp. $35-44$.

Feldman, A. \& Acredolo, L. (1979). The effect of active vs passive exploration on memory for spatial location in children. Child Development, 50, 698-704.

Foulke, E. (1983). Spatial ability and the limitations of perceptual systems. In H. L. Pick \& L. J. Acredolo, Eds., Spatial Orientation: Theory, Research and Application, New York, NY: Plenum Press, pp. 125-141.

Gale, N. (1982). Some applications of computer cartography to the study of cognitive configurations. Professional Geographer, 34(3), 313-321.

Garling, T. (1989). The role of cognitive maps in spatial decisions. Journal of Environmental Psychology, 9, 269-278.

Garling, T., Book, A., Lindberg, E. \& Nilsson, T. (1981). Memory for the spatial layout of the everyday physical environment: factors affecting rate of acquisition. Journal of Environmental Psychology, 1, 263-277.

Garling, T., Book, A. \& Lindberg, E. (1985). Adults' memory representations of the spatial properties of their everyday physical environment. In R. Cohen, Ed., The Development of Spatial Cognition, Hillsdale, NJ: Erlbaum Lawerence, pp. 141-184.

Garling, T. \& Evans, G. W (1991). Environment, Cognition and Action-An integrated approach. New York, NY: Oxford University Press.

Garling, T. \& Golledge, R. G. (1989). Environmental perception and cognition. In E. Zube \& G. Moore, Eds., Advances in Environmental Behaviour and Design. New York, NY: Plenum Press, Vol. 2, 203-236.

Garling, T. \& Golledge, R. G. (Eds) (1993). Behaviour and Environment: Psychological and Geographical approaches. North Holland: Elsevier Press.

Garling, T., Lindberg, E., Carreiras, M. \& Book, A. (1986). Reference systems in cognitive maps. Journal of Environmental Psychology, 6, 1-18.

Gatrell, A. C. (1983). Distance and Space: A Geographical Perspective. London: Claredon.

Gilmartin, P. (1985). The cued spatial response approach to macro-scale cognitive maps. Canadian Geographer, 29(1), 56-59.

Gilmartin, P. (1986). Maps, mental imagery and gender in the recall of geographical information. American Cartographer, 13, $335-344$.

Gilmartin, P. \& Lloyd, R. (1991). The effects of map projections and map distance on emotional involvement with places. Cartographic Journal, 28, 145-151.
Gilmartin, P. \& Patton, J. C. (1984). Comparing the sexes on spatial abilities: map-use skills. Annals of the Association of American Geographers, 74, 605-619.

Gluck, M. (1991). Making sense of human wayfinding: review of cognitive and linguistic knowledge for personal navigation with a new research direction. In D. M. Mark \& A. U. Frank, Eds., Cognitive and Linguistic Aspects of Geographic Space. Kluwer Academic Publishers, pp. 117-135.

Gold, J. R. \& Goodey, B. (1987). Behavioral and perceptual geography: criticisms and response. Progress in Human Geography, 8(4), 544-550.

Goldberg, M. A. (1983). The irrationality for 'rational planning': exploring broader bases for planning and public decision making. In M. J. Breheny \& A. J. Hooper, Eds., Rationality in planning: critical essay on the role of rationality in urban and regional planning. London: Pion.

Golledge, R. G. (1977). Environmental cues, cognitive mapping spatial behaviour. In D. Burke, et al., Eds., BehaviourEnvironment research methods. Institute for Environmental studies, University of Winsconsin, WI: pp. 35-46.

Golledge, R. G. (1981). Misconceptions, misinterpretations, and misrepresentations of behavioral approaches in human geography. Environment \& Planning, A13, 1315-1344.

Golledge, R. G. (1985). Teaching behavioral geography. Journal of Geography in Higher Education, $\mathbf{9}(2), 111-127$

Golledge, R. G. (1992). Place recognition and wayfinding: making sense of space, Geoforum, 23(2), 199-214.

Golledge, R. G., Gale, N., Pellegrino, J. W. \& Doherty, S. (1992). Spatial knowledge acquisition by children: route learning and relational distances. Annals of the Association of American Geographers, 82(2), 223-244.

Golledge, R. G., Parnicky, J. J. \& Rayner, J. N. (1979). An experimental design for assessing the spatial competence of mildly retarded populations. Social Science \& Medicine, 13D, 291-295.

Golledge, R. G., Richardson, G. D., Rayner, J. N. \& Parnicky, J. J. (1983). Procedures for defining and analyzing cognitive maps of the mildly and mentally retarded. In H. L. Pick \& L, J. Acredolo, Eds., Spatial Orientation: Theory, Research and Application. New York, NY: Plenum Press, pp. 79-104.

Golledge, R. G., Rivizzigno, V. \& Spector, A. N. (1976). Learning about the city: analysis by multidimensional scaling. In R. Golledge \& G. Rushton, Eds., Spatial Choice and Spatial Behaviour. Columbus, OH: Ohio State University Press, pp. 95-116.

Golledge, R. G., Smith, T. R., Pellegrino, J. W., Doherty, S. \& Marshall, S. P. (1985). A conceptual model and empirical analysis of childrens acquisition of spatial knowledge. Journal of Environmental Psychology, 5, 125-152.

Golledge, R. G. \& Stimson, R. J. (1987). Analytical Behavioral Geography. London: Croom Helm.

Golledge, R. G. \& Timmermanns, H. (1990). Applications of behavioral research on spatial problems I: cognition. Progress in Human Geography, 14(1), 57-99.

Goodchild, B. (1974). Class differences in environmental perception: an exploratory study. Urban Studies, 11, 157-169.

Goodey, B. \& Gold, J. R. (1985). Behavioral and perceptual geography: from retrospect to prospect. Progress in Human Geography, 9(4), 585-595.

Gopal, S., Klatzky. R. L. \& Smith, T. R. (1989). NAVIGATOR: a psychologically based model of environmental learning through navigation. Journal of Environmental Psychology, 9, 309-331.

Gould, M. D. (1991). Elicitation of spatial language to support cross-cultural Geographic Information Systems. In D. M. Mark 
\& A. U. Frank, Eds., Cognitive and Linguistic Aspects of Geographic space. Kluwer Academic Publishers, pp. 435448.

Gould, P. (1969). The structure of space preferences in Tanzania. Area, 4, 29-35.

Gould, P. (1983). Getting involved in information and ignorance. Journal of Geography, 82, 158-162.

Gould, P. \& White, R. (1974). Mental maps, New York, NY: Penguin.

Graham, E. (1976). What is a mental map? Area, 9, 259-262.

Graham, E. (1982). Maps, metaphors and muddles. Professional Geographer, 34, 251-260.

Griffin, P. (1948). Topological orientation. In E. G. Boring et al. Eds., Foundations in Psychology. New York, NY: John Wiley, pp 380-386.

Hart, R. A. \& Conn, M. K. (1991). Developmental perspectives on decision making and action in environments. In T. Garling \& G. W. Evans, Eds., Environment, Cognition and Action-An Integrated Approach. New York, NY: Plenum Press pp. 277294.

Hart, R. A. \& Moore, G. (1973). The development of spatial cognition: a review. In R. M. Downs \& D. Stea, Eds., Image and Environment. Chicago, IL: Aldine, pp. 246-288.

Hazen, N. L., Lockman, J. J \& Pick, H. L. (1978). The development of childrens representations of large scale environments. Child development, 49, 623-636.

Hernandez, D. (1991). Relative representation of spatial knowledge: the 2-D case. In D. M. Mark \& A. U. Frank, Eds., Cognitive and Linguistics Aspects of Geographic Space. Kluwer Academic Publishers, pp. 373-385.

Hill, F. \& Michelson, W. (1981). Towards a geography of urban children and youth. In D. T. Herbert \& R. J. Johnston, Eds., Geography and the Urban Environment: Progress in Research and Applications, Vol. 4, Chichester: Wiley.

Jahoda, G. (1979). On the nature of difficulties in spatialperceptual tasks: ethnic and sex-differences. British Journal of Psychology, 70, 351-363.

Johnston, R. J. (1972). Activity spaces and residential preferences: some tests of the hypothesis of sectoral mental maps. Economic Geography, 48, 199-211.

Kail, R., Carter, P. \& Pellegrino, J. (1980). The locus of sex differences in spatial ability. Perception and Psychophysics, $\mathbf{2 6}$, 182-186.

Kaplan, S. (1973a). Cognitive maps in perception and thought. In R. M. Downs \& D. Stea, Eds., Image and Environment. Chicago, IL: Aldine, pp. 63-78.

Kaplan, S. $(1973 b)$. Cognitive maps, human needs, and the designed environment. In W. F. E. Preisner, Ed., Environmental Design Research. Stroudsberg, PA: Dowden, Hutchinson \& Ross, Vol. 1, p. 275-283.

Kaplan, S. (1976). Adaptation, structure \& knowledge. In G. T. Moore \& R. G. Golledge, Eds., Environmental Knowing. Stroudsberg, PA: Dowden, Hutchinson \& Ross, pp. 32-45.

Kirasic, K. C. (1985). A roadmap to research for spatial cognition in the elderly adult. In R. Cohen, Ed., The Development of Spatial cognition. Hillsdale, NJ: Erlbaum Lawerence, pp. 185-198.

Kirasic, K. C. (1989). The effects of age and environmental familiarity on adults spatial problem-solving performance: evidence of a hometown advantage. Experimental Aging Research, 15(4), 181-187.

Kirasic, K. C. (1991). Spatial cognition and behaviour in young and elderly adults: Implications for learning new environments. Psychology and Aging, 6(1), 10-18.
Kirasic, K. C., Allen, G. \& Haggerty, D. (1992). Age-related differences in adults macrospatial cognitive processes. Experimental Aging Research, 18(1), 33-39.

Kuipers, B. (1978). Modelling spatial knowledge. Cognitive Science, 2, 129-153.

Kuipers, B. (1982). The 'map in the head' metaphor. Environment and Behaviour, 14(2), 202-220.

Kuipers, B. (1983). The cognitive map: could it have been any other way? In H. L. Pick \& L. J. Acredolo, Eds., Spatial Orientation: Theory, Research and Application. New York, NY: Plenum Press, pp. 345-359.

Kuipers, B. \& Levitt, T. (1988). Navigation and mapping in largescale space. AI Magazine, 9(2), 25-46.

Lee, T. (1968). Urban neighbourhood as a social-spatial schema. Human Relations, 21, 241-262.

Levitt, T. S., Lawton, D. T., Chelberg, D. M., Koitzsch, K. \& Dye, J. W. (1988). Qualitative navigation 2. Proceedings of the DARPA Image Understanding Workshop. Los Altos, CA: Morgan Kaufman, pp. 319-326.

Levitt, T. S., Lawton, D. T., Chelberg, D. M. \& Nelson, P. C. (1987). Qualitative landmarked based path planning and following. Proceedings American Association of Artificial Intelligence National Conference (AAAI-1987), pp. 689-694.

Leiser, D. \& Zilbershatz, A. (1989). The traveller: a computational model of spatial network learning. Environment and Behaviour, 22, 435-464.

Liben, L. (1981). Spatial representation and behaviour: multiple perspectives. In L. S. Liben, A. M. Patterson \& N. Newcombe, Eds., Spatial Representation and Behaviour Across the Life Span. New York, NY: Academic Press.

Liben, L. S. (1991). Environmental cognition through direct and representational experiences: A life-span perspective. In $\mathrm{T}$. Garling \& G. W. Evans, Eds., Environment, Cognition and Action-An Integrated Approach. New York, NY: Plenum Press, pp. 245-276.

Liben, L. S. \& Golbeck, S. L. (1980). Sex differences in performance on Piagetian spatial tasks: difference in competence or performance? Child Development, 51, 594-597.

Lieblich, I. \& Arbib, M. A. (1982). Multiple representations of space underlying behaviour \& associated commentaries. The Behavioral and Brain Sciences, 5(4), 627-660.

Lloyd, R. (1982). A look at images. Annals of the Association of American Geographers, 72, 532-548.

Lloyd, R. (1989) The estimation of distance and direction from cognitive maps. The American Cartographer, 16(2), 109-122.

Lowery, R. A. (1973). A method for analyzing distance concepts of urban residents. In R. M. Downs \& D. Stea, Eds., Image and Environment. Chicago, IL: Aldine, pp. 338-360.

Lynch, K. (1960). The Image of the City. Cambridge, MA: MIT Press.

Lynch, K. (1976). Preface. In G. T. Moore \& R. G. Golledge, Eds., Environmental Knowing, Stroudsberg, PA: Dowden, Hutchinson \& Ross.

Lynch, K. (1977). Growing Up in Cities. Cambridge, MA: MIT Press.

MacEachren, A. M. (1991). The role of maps in spatial knowledge acquisition. Cartographic Journal, 28, 152-162.

MacEachren, A. M. (1992). Application of environmental learning theory to spatial knowledge acquisition from maps. Annals of the Association of American Geographers, 82(2), 245-274.

McCalla, G. I., Reid, L. \& Schneider, P. K. (1982). Plan creation, plan execution and knowledge acquisition in a dynamic microworld. International Journal for Man-Machine Studies, 16, 89-112. 
McDermott, D. \& Davis, E. (1984). Planning routes through uncertain territory. Artificial Intelligence, 22, 107-156.

Mark, D. M. (1989). Cognitive image-schemata for geographic information: relations to user views and GIS interfaces, Proceedings of GIS / LIS 2, Orlando, FL.

Mark, D. M. \& Gould, M. D. (1991). Interacting with geographic information: a commentary. Photogrammatic Engineering and Remote Sensing, 57(11), 1427-1430.

Matthews, M. H. (1980). The mental maps of children. Geography, 65, 169-179.

Matthews, M. H. (1984). Cognitive maps: a comparison of graphic and iconic techniques. Area, 16, 33-40.

Matthews, M. H. (1986). Gender, home range and environmental cognition. Transactions of the Institute of British Geographers, NS12, 43-56.

Matthews, M. H. (1992). Making Sense of Place: Childrens Characterisation of Place. Hemel Hempstead: Harvester Wheatsheaf.

Medyckyj-Scott, D. \& Blades, M. (1992). Human spatial cognition: its relevance to the design and use of spatial information systems. Geoforum, 23(2), 215-226.

Medyckyj-Scott, D., Newman, I. A., Ruggles, C. \& Walker, D. (1990). Usability testing in user interface design for GIS and the role of rapid processing. Proceedings of the First European GIS Conference. Amsterdam.

Montello, D. R. (1989). The geometry of environmental knowledge. In A. U. Frank, I. Campari \& V. Formentini, Eds., Theories and Methods of Spatio-temporal Reasoning in Geographic Space. Berlin: Springer-Verlag, Lecture notes in computer science no. 639 .

Moore, G. \& Golledge, R. (1976). Environmental knowing: concepts and theories. In G. T, Moore \& R. G. Golledge, Eds., Environmental Knowing. Stroudsberg, PA: Dowden, Hutchinson and Ross, pp. 3-24.

Moore, G. T. (1976). Theory and research on the development of environmental knowing. In G. T. Moore \& R. G. Golledge, Eds., Environmental Knowing. Stroudsberg, PA: Dowden, Hutchinson \& Ross, pp. 138-164.

Moore, G. T. (1979). Knowing about environmental knowing: the current state of theory and research on environmental cognition. Environment and Behaviour, 11, 33-70.

Neisser, U. (1976). Cognition and Reality. San Francisco, CA: Freeman.

Newcombe, N. (1982). Development of spatial cognition and cognitive development. In R. Cohen, Ed., Children's Conceptions of Spatial Relationships. San Francisco, CA: Jossey-Bass, pp. 65-82.

Newcombe, N. (1985). Method for the study of spatial cognition. In R. Cohen, Ed., The Development of Spatial Cognition, Hillsdale, NJ: Erlbaum Lawerence, pp. 1-12.

O'Keefe, J. \& Nadel, J. (1978). The Hippocampus as a Cognitive Map. Oxford: Claredon Press.

Ohta, R. J. (1983). Spatial orientation in the elderly: the current status of understanding. In H. L. Pick \& L. J. Acredolo, Eds., Spatial Orientation: Theory, Research and Application. New York, NY: Plenum Press, pp. 105-123.

Ohta, R. J. \& Kirasic, K. C. (1983). Learning about environmental learning in the elderly adult. In G. Rowles \& J. Ohta, Eds., Aging and Milieu: Environmental Perspectives on Growing Old. New York, NY: Academic Press, pp. 83-95.

Pacione, M. (1978). Information and morphology in cognitive maps. Transactions of the Institute of British Geographers, NS3, 548-568.

Pacione, M. (1982). Space preferences, location distances, and the dispersal of civil servants from London. Environment \& Planning A, 323-333.

Passini, R. (1992). Wayfinding in Architecture. New York, NY: Van Nostrand Reinhold.

Piaget, J. \& Inhelder, B. (1956). The Child's Conception of Space. London: Routledge \& Kegan Paul.

Pocock, D. C. D. (1972). The city in the mind: a review of mental maps in urban areas. Scottish Geographical Magazine, 88, 116-124.

Pocock, D. C. D. (1973). Environmental perception: process and product. Tijdschrift Voor Econmische en Social Geografie, 64, 251-257.

Pocock, D. C. D. (1980). The cognition of intra-urban distance-A summary. Scottish Geographical Magazine, 94, 31-35.

Regnier, V. (1983). Urban neighbourhood cognition: relationships between functional and symbolic community elements. In G. D. Rowles \& R. J. Ohta, Eds., Aging and Milieu: Environmental Perspectives on Growing Old. New York, NY: Academic Press, pp. 63-82.

Saarinen, T. F. (1973). Student views of the world. In R. M. Downs \& D. Stea, Eds., Image and Environment. Chicago, IL: Aldine, pp. 148-161.

Saarinen, T. F. (1988). Centring of mental maps of the World. National Geographic Research, 4(1), 112-127.

Saarinen, T. F., MacCabe, C. L. \& Morehouse, B. (1988). Sketch maps of the world as surrogates for world geographic knowledge, Paper 83-3, Department of Geography Regional Development, University of Arizona, Tucson.

Saarinen, T. F., Parton, M. \& Billberg, R. (1992). Relative size of continents on world sketch maps. Paper 92-6, Department of Geography and Regional. Development, University of Arizona, Tucson.

Saisa, J., Svensson-Garling, A., Garling, T. \& Lindberg, E. (1986). Intraurban cognitive distance: the relationship between judgements of straight line distances, travel distances, and travel times. Geographical Analysis, 18(2), 167-174.

Seelig, J. \& Seelig, M. (1986). The new physical planning: linking intuition and limits. Journal of Architectural and Planning Research, 3(1), 1-14.

Self, C. M., Gopal, S., Golledge, R. G. \& Fenstermaker, S. (1992). Gender-related differences in spatial abilities. Progress in Human Geography, 16(3), 315-342.

Shemyakin, F. N. (1962): Orientation in space. In B. G. Ananyev et al. Eds., Psychological science in the U.S.S.R. Report No. 62-11083. Washington, DC: Office of Technical Services, Vol. 1 186-255.

Siedel, A. (1985). What is success in $\mathrm{E} \& \mathrm{~B}$ research? Environment \& Behaviour, 17, 47-70.

Siegel, A. W. (1981). The externalisation of cognitive maps by children and adults: In search of ways to ask better questions. In L. S. Liben, A. Patterson \& N. Newcombe, Eds., Spatial Representation and Behaviour Across the Life Span. New York, NY: Academic Press.

Siegel, A. W. \& Cousins, J. H. (1985). The symbolizing and symbolised child in the enterprise of cognitive mapping. In $R$. Cohen, Ed., The Development of Spatial Cognition. Hillsdale, NJ: Lawerence Erlbaum.

Smith, T. R., Pellegrino, J. W. \& Golledge, R. G. (1982). Computational process modelling of spatial cognition and behaviour. Geographical Analysis, 14, 305-325.

Spencer, C. \& Blades, M. (1986). Pattern and process: a review essay on the relationship between behavioral geography and environmental psychology. Progress in Human Geography, 10, 230-248. 
Spencer, C., Blades, M. \& Morsley, K. (1989). The Child in the Physical Environment. Chichester: Wiley.

Spencer, C. \& Weetman, M. (1981). The microgenesis of cognitive maps: a longitudinal study of new residents of an urban area. Transactions of the Institute of British Geographers, 6, 375384.

Stea, D. (1969). The measurement of mental maps: An experimental model for studying conceptual spaces. In $K$. Cox \& R. G. Golledge, Eds., Behavioral Problems in. Geography. Evanston, IL: Northwestern Studies in Geography, pp. 228- 253.

Stea, D. (1976). Notes on a spatial fugue. In G. T. Moore \& R. G. Gollege, Eds., Environmental Knowing, Stroudsberg, PA, Dowden, Hutchinson \& Ross.

Stea, D. \& Blaut, M. (1973). Some preliminary observations on spatial learning in school children. In R. M. Downs \& D. Stea, Eds., Image and Environment. Chicago, IL: Aldine, pp 226-234.

Thorndyke, P. W. (1981). Distance estimation from cognitive maps. Cognitive Psychology, 13, 526-550.

Thorndyke, P. W. \& Hayes-Roth, B. (1982). Differences in spatial knowledge acquired from maps and navigation. Cognitive Psychology, 14, 560--589.

Thorndyke, P. W. \& Statz, C. (1980). Individual differences in procedures for knowledge acquisition from maps and navigation. Cognitive Psychology, 12, 137-175.

Tolman, E. C. (1948). Cognitive maps in rats and men. Psychological Review, 55, 189-208.

Tuan, Y. F. (1975). Images and mental maps. Annals of the Association of American Geographers, 65(2), 205-213.

Turk, A. G. (1990). Towards an understanding of human- computer interaction aspects of Geographic Information Systems. Cartography, 19(1), 31-60.

Tversky, B. (1981). Distortions in memory for maps. Cognitive Psychology, 13, 407-433.

Tversky, B. (1992). Distortions in cognitive maps. Geoforum, 23(2), 131-138.

Walmsley, D. J., Saarinen, T. F. \& MacCabe, C. L. (1990). Down under or centre stage? The world images of Australian students. Australian Geographer, 21(2), 164-173.

Webber, M. J., Symanski, R. \& Root, J. (1975). Toward a cognitive spatial theory. Economic Geography, 51, 100-116.

Webley, P. \& Whalley, A. (1987). Sex differences in childrens environmental cognition. Journal of Social Psychology, 127, 323-325.

West, R. L., Morris, C. W. \& Nichol, G. T. (1985). Spatial cognition on nonspatial tasks: Finding spatial knowledge when you're not looking for it. In R. Cohen, Ed., The Development of Spatial Cognition. Hillsdale, NJ: Erlbaum Lawerence, pp. 13-39.

Wood, D. \& Beck, R. (1990). Tour personality: The interdependance of environmental orientation and interpersonal behaviour. Journal of Environmental Psychology, 10, 177-207.

Zimring, C. \& Gross, M. (1991). Searching for the environment in environmental cognition research. In T. Garling \& G. W. Evans, Eds., Environment, Cognition and Action-An Integrated Approach. New York, NY: Oxford University Press, pp. 78-95.

Manuscript received 16 September 1993 Revised manuscript received 12 January 1994 